\title{
Metabolic effects of an ATI-receptor blockade combined with HCTZ in cardiac risk patients: a non interventional study in primary
}

\section{care}

\author{
Peter Bramlage*1, Eleonore Schönrock ${ }^{2}$ and Peter Odoj ${ }^{3}$
}

\author{
Address: ${ }^{1}$ Institute for Clinical Pharmacology, Medical Faculty Carl Gustav Carus, TU Dresden, Germany, ${ }^{2}$ General Practitioner, Potsdam, Germany \\ and ${ }^{3}$ General Practitioner, Kirchlengern, Germany \\ Email: Peter Bramlage* - peter.bramlage@mailbox.tu-dresden.de; Eleonore Schönrock - peter.bramlage@mailbox.tu-dresden.de; \\ Peter Odoj - peter.bramlage@mailbox.tu-dresden.de \\ * Corresponding author
}

Published: 10 November 2008

BMC Cardiovascular Disorders 2008, 8:30 doi:10.1186/1471-2261-8-30

This article is available from: http://www.biomedcentral.com/|47|-226I/8/30

(c) 2008 Bramlage et al; licensee BioMed Central Ltd.

This is an Open Access article distributed under the terms of the Creative Commons Attribution License (http://creativecommons.org/licenses/by/2.0), which permits unrestricted use, distribution, and reproduction in any medium, provided the original work is properly cited.
Received: 29 February 2008

Accepted: 10 November 2008

\begin{abstract}
Background: The reduction of blood pressure alone does not eliminate the increased risk of arterial hypertension. Whilst concomitant metabolic risk factors have been shown to be responsible, the available pharmacotherapy has differential effects on these metabolic risk factors. For example, diuretics and betablockers worsen glucose metabolism, hence the starting point of the current subanalysis of the CHILI (Candesartan in patients with Hlgher cardiovascuLar rlsk) study was the assumption that an angiotensin receptor blocker may counterbalance the metabolic effects of a low dose diuretic in patients with several metabolic risk factors.
\end{abstract}

Methods: The present study was performed as a non-interventional observational study in Germany. Patients with previously uncontrolled hypertension with at least one further risk factor in which physicians deemed a treatment with $16 \mathrm{mg}$ Candesartan/I2.5 mg HCTZ to be necessary were included. The risk factors were calculated in patient subgroups with diabetes, the metabolic syndrome (MetSyn) and neither condition (control). The risk of cardiovascular mortality within the next 10 years was calculated using the SCORE algorithm of the ESC.

Results: Between August 2006 and February 2007 a total of 3,787 patients were included into the non-interventional trial. Patients were $62.2 \pm 11.3$ years old, $48.1 \%$ were female, $97.5 \%$ had at least one additional risk factor. Blood pressure was reduced by $-27.2 /-13.4 \mathrm{mmHg}$ with only minor non significant variations between patient groups. Waist circumference was reduced $(P<0.000 \mathrm{I})$ and HDL-C elevated $(P<0.05)$ in every subgroup except the control subgroup. Fasting blood glucose was reduced by $-5.6 \pm 21.6 \%(P<0.0001$ vs. baseline and vs. control $)$ as well as triglycerides $(-4.9$ $\pm 29.4 \% ; \mathrm{P}<0.000 \mathrm{I}$ vs. baseline and vs. control). The SCORE value was reduced substantially (-8.7, -3.2 and $-2.7 \%$ in patients with diabetes, the metabolic syndrome or neither).

Conclusion: The present study demonstrates that a $16 \mathrm{mg}$ candesartan/I2.5 mg HCTZ based treatment results in a pronounced blood pressure reduction and was associated with a favourable change in metabolic risk factors such as HDL cholesterol, triglycerides and blood glucose. These data indicate that metabolic effects observed in clinical trials like ALPINE, SCOPE or CHARM can also be observed in an unselected patient population in primary care. 


\section{Background}

Arterial hypertension is one of the most prevalent risk factors for cardiovascular disease [1-3] and an important cause of death worldwide [4]. The relationship between blood pressure and cardiovascular risk is almost linear in patients without end organ damage $[5,6]$ and an arbitrary threshold of 140/90 mmHg has been defined to simplify diagnosis and treatment approaches in daily practice [7]. Lifestyle interventions have been proposed to lower blood pressure and cardiovascular risk [8], but they often fail to be long-term solutions. Therefore a number of anti-hypertensive drugs have been developed, giving clinicians many options. Whilst lowering BP is a mainstay of cardiovascular risk reduction, it is important to treat the other cardiovascular risk factors as well [9].

Hypertension is frequently found together with other metabolic risk factors (low HDL-Cholesterol, abdominal obesity, high triglycerides, high fasting blood glucose etc.). The HOT study for example found that each of the risk factors considered was an important cause of residual risk, despite good blood pressure control [9]. It therefore seems to be of principal importance to address other correctable risk factors and to be particularly conscious about the metabolic effects of antihypertensive drugs even in patients being treated to goal $(120 / 80 \mathrm{mmHg})$.

In a recent meta-analysis Elliott and colleagues [10] showed that increased blood sugar values and the subsequent development of diabetes occur more often in patients receiving diuretics and betablockers instead of angiotensin receptor blockers (ARBs) and angiotensin converting enzyme (ACE) inhibitors. Furthermore it was recently demonstrated that patients on betablockade have more difficulties to reduce abdominal obesity and additional metabolic risk factors than those patients on a combination of renin-angiotensin system (RAS) blocking agents and Calcium Channel Blockers (CCBs) [11]. Of note, the $\mathrm{ARB}$, candesartan reduced the number of patients developing diabetes in the CHARM [12], SCOPE [13] and ALPINE: [14] trial. When candesartan was administered to a group of hypertensive subjects it caused a reduction in C-reactive protein and an increase in adiponectin and markers of insulin sensitivity; as measured by QUICKI (Quantitative Insulin-Sensitivity Check Index) index [15].

Of particular interest within this context is a combination of candesartan with a low dose diuretic (12.5 mg hydrochlorothiazide, HCTZ) and to test whether the properties of both agents combine to create a beneficial outcome for patients. It was therefore the aim of the present analysis of the non interventional CHILI (Candesartan in patients with HIgher cardiovascuLar rIsk) study to investigate the influence of candesartan in fixed combination with HCTZ on a number of metabolic parameters and cardiovascular risk factors in more detail. The study was conducted in a primary care setting in order to acquire the broadest possible spectrum of patients in clinical practice. Three core questions were to be answered: 1) reduction in blood pressure; 2) reduction of cardiovascular risk factors like fasting glucose, waist circumference, triglycerides, HDLCholesterol after 8 week treatment and differential effects in patients with diabetes, the metabolic syndrome and neither disease state; 3 ) change in the absolute 10 year risk of cardiovascular morbidity (using the SCORE method) and the contribution of a) blood pressure and b) metabolic effects to this effect.

\section{Methods}

The present non-interventional study was conducted between August 2006 and February 2007 with the help of 893 primary care physicians all over Germany. Therefore a sample of general practitioners, internists, cardiologists and practical physicians was drawn from all segments of the Institute for Medical Statistics (IMS, Frankfurt, Germany). The study was duly notified according to local laws and regulations ( $\$ 67$ (6) Arzneimittelgesetz, AMG) to the higher authorities (Bundesinstitut für Arzneimittel und Medizinprodukte, BfArM) and the federal panel doctors' association (Kassenärztliche Bundesvereinigung, KBV). Approval was obtained by the Technical University Dresden ethical committee. Due to regulations for this kind of study no patient informed consent had to be obtained. Methods of this study have been published previously [16].

\section{Patients}

Patients were at least 18 years old, had essential arterial hypertension with blood pressure values beyond 140/90 $\mathrm{mmHg}$ (> 130/85 mmHg in diabetic patients) and previous antihypertensive therapy of at least 8 weeks duration had proven unsuccessful. In addition to this one of the following risk factors had to be present: Diabetes mellitus, dyslipidemia, abdominal obesity, hs-CRP $\geq 2 \mathrm{mg} / \mathrm{l}$ or confirmation of microalbuminaria (MAU). Patients who fulfilled these criteria and who's treating physician deemed a treatment with $16 \mathrm{mg}$ Candesartan/12.5 mg HCTZ to be necessary were documented.

\section{Metabolic Syndrome definition}

The AHA/NHLBI 2004 definition was used to determine the presence of the metabolic syndrome [17]. It requests that 3 out of the following 5 criteria are met: 1 ) waist circumference $>102 \mathrm{~cm}$ in men and $>88 \mathrm{~cm}$ in women; 2 ) blood pressure readings $\geq 130 \mathrm{mmHg}$ systolic or $\geq 85$ mmHg diastolic; 3 ) fasting glucose $\geq 5.6 \mathrm{mmol} / \mathrm{L} \mathrm{(} \geq 100$ $\mathrm{mg} / \mathrm{dL}$ ) or known diabetes mellitus; 4 ) triglycerides $\geq 1.7$ $\mathrm{mmol} / \mathrm{l}(\geq 150 \mathrm{mg} / \mathrm{dL}) ; 5)$ HDL-Cholesterol $<1.0 \mathrm{mmol} /$ 
$\mathrm{L}(40 \mathrm{mg} / \mathrm{dL})$ in men, and $<1.3 \mathrm{mmol} / \mathrm{L}(50 \mathrm{mg} / \mathrm{dL})$ in women.

\section{Calculation of the SCORE value}

The following parameters were used for the calculation of the score [18]: sex, age, HDL-C, total cholesterol (either indicated or calculated by the Friedewald formula), systolic BP and smoking status. In the presence of diabetes, the score was increased by a factor of 2 in men and by a factor of 4 in women. Calculations were done without replacement of missing values. To calculate the blood pressure risk reduction attributable to diabetes, the baseline SCORE risk was modified by replacing the blood pressure baseline value by the 8 week follow-up value but keeping the baseline values for metabolic risk factors. To calculate the risk attributable to metabolic changes, baseline SCORE risk was modified by replacing the baseline values of metabolic parameters by the 8 week values but keeping the baseline blood pressure within the model.

\section{Study conduct}

Physicians were asked to document at least 3 patients with arterial hypertension and concomitant cardiovascular risk factors. The observational period was 8 weeks and patients had a voluntary additional visit at 4 weeks and the case report forms were retrieved by the CRO Christine Franzen Consulting, (Stolberg, Germany) and screened routinely for plausibility and completeness. Source data verification was however not performed. Confidentiality: Patient data were recorded anonymously (age and gender only). Electronic data processing was conducted in accordance with local laws and regulations and the participating GPs received remuneration for the documentation of each patient which was in accordance with the "Gebührenordnung für Ärzte" (GOÄ).

\section{Statistical Analyses}

Regarding safety, the trial was adequately sized ( $\mathrm{n}=$ 3,787 ) to identify rare AEs, i.e. those that may not have been detected in previous clinical studies, (incidence 1 : 1,000 ) with a probability of $>99 \%$. These data have been published previously [16]. The statistical analysis was performed descriptively and was interpreted in an explorative way. Comparisons were made for a number of variables and analyzed using descriptive statistics. The number of patients is given for each value and differences were calculated in patients with values at baseline and follow-up (per protocol). The analysis of data was performed with ACCESS 2003 and Winstat for Microsoft Excel. Tests applied are indicated in the legends of tables and figures.

\section{Results}

3,787 patients were included into the present study. The patients had a mean age of $62.2 \pm 11.3$ years, $48.1 \%$ were female and BMI was $29.5 \pm 4.7 \mathrm{~kg} / \mathrm{m}^{2} .97 .5 \%$ had at least one cardiovascular risk factor, $29.8 \%$ existing cardiovascular disease. $13.0 \%$ of patients had angina pectoris, $12.5 \%$ heart failure, $8.4 \%$ myocardial infarction, $6.2 \%$ kidney failure and $4.9 \%$ previous stroke.

\section{Cardiovascular risk factors over time}

The risk factors making up the metabolic syndrome were elevated throughout all patient subgroups (metabolic syndrome, with diabetes mellitus and neither condition) with hypertension (inclusion criterion), dyslipidemia (78.2\%) and abdominal obesity (65.4\%) being the most frequent. Tables 1, 2 and 3 display the course of these risk factors throughout the study in patients with the metabolic syndrome, with diabetes mellitus and neither condition. Blood pressure was significantly reduced in all patients $(-27.2 /-13.4 \mathrm{p}<0.0001)$ and there was no significant difference between the extent of blood pressure lowering $(\mathrm{p}=\mathrm{n} . \mathrm{s}$.) between groups. Fasting blood glucose and triglycerides were unchanged in patients without the metabolic syndrome or diabetes only ( $p=n . s$.); every other parameter was significantly changed versus baseline in a positive direction.

\section{Comparison between different patient groups}

Figure 1 displays the relative change in risk factors in comparison between the three groups of patients. While fasting plasma glucose was unchanged $(\mathrm{p}=\mathrm{n}$.s. $)$ in patients with neither the metabolic syndrome nor diabetes it was gradually reduced in patients with the metabolic syndrome $(-1.6 \pm 12.1 \%$; $p<0.0001$ vs. baseline $)$ and strongly reduced in patients with diabetes $(-5.6 \pm 21.6 \%$; $\mathrm{p}<0.0001$ vs. baseline). This corresponded to a mean absolute reduction of $-2.5 \pm 13.1$ and $-10.8 \pm 30.1 \mathrm{mg} / \mathrm{dL}$ respectively. Triglycerides were similarly unchanged in the control group while they were reduced in MetSyn (-4.1 \pm $43.9 \% ; \mathrm{p}<0.0001$ vs. baseline) and Diabetes $(-4.9 \pm$ $29.4 \% ; \mathrm{p}<0.0001)$. Mean absolute values were $-19.1 \pm$ 61.0 and $-23.3 \pm 76.2 \mathrm{mg} / \mathrm{dl}$ respectively.

\section{Absolute cardiovascular risk in comparison to normal age matched controls}

Finally absolute cardiovascular risk was calculated according to the SCORE method. The baseline risk differed substantially in the three patient subgroups (Diabetes $19.8>$ MetSyn $7.4>$ Neither $6.4 \%$ ) as did the absolute risk reduction (Diabetes -8.7 > MetSyn -3.2> Neither -2.7\%). For details see table 4 . The SCORE value was also calculated assuming that a) blood pressure was unchanged (risk reduction of $-2.6,-2.9$ and $-7.6 \%$ in patients with neither, MetSyn or diabetes respectively) and b) that all other risk factors were unchanged $(-0.4,-0.7$ and -1.4$)$ to estimate the proportion of risk reduction from the antihypertensive effect of candesartan (Table 4). 
Table I: Cardiovascular risk factors at baseline and follow-up in patients without the metabolic syndrome I and diabetes mellitus ${ }^{2}$

\begin{tabular}{|c|c|c|c|c|c|c|c|c|c|c|}
\hline & & $\mathbf{N}$ & $\begin{array}{l}\text { Baseline } \\
\text { mean }\end{array}$ & \pm SD & $\mathbf{N}$ & $\begin{array}{l}8 \text { weeks } \\
\text { mean }\end{array}$ & \pm SD & $\mathbf{N}$ & $\begin{array}{l}\text { difference }^{2} \\
\text { mean }\end{array}$ & \pm SD \\
\hline \multicolumn{11}{|c|}{ Blood pressure } \\
\hline systolic & $\mathrm{mmHg}$ & 354 & 159.8 & 14.7 & 348 & 133.0 & 10.8 & 341 & $-27.0 *$ & 14.5 \\
\hline diastolic & $\mathrm{mmHg}$ & 353 & 93.3 & 9.3 & 348 & 80.7 & 6.0 & 340 & $-12.8^{*}$ & 10.1 \\
\hline \multicolumn{11}{|c|}{ Fasting plasma glucose } \\
\hline & $\mathrm{mg} / \mathrm{dL}$ & 354 & 85.9 & 11.5 & 205 & 86.8 & 14.5 & 203 & 1.7 & 15.0 \\
\hline \multicolumn{11}{|c|}{ Waist circumference } \\
\hline men & $\mathrm{cm}$ & 141 & 97.9 & 10.4 & 135 & 96.8 & 9.7 & 133 & $-0.8^{*}$ & 1.9 \\
\hline women & $\mathrm{cm}$ & 142 & 88.8 & 11.7 & 130 & 87.8 & 10.5 & 130 & $-0.6 *$ & 2.8 \\
\hline \multicolumn{11}{|c|}{ Triglycerides } \\
\hline & $\mathrm{mg} / \mathrm{dL}$ & 351 & 138.0 & 80.6 & 197 & 137.7 & 57.6 & 195 & 0.3 & 3.86 \\
\hline \multicolumn{11}{|c|}{ HDL Cholesterol } \\
\hline men & $\mathrm{mg} / \mathrm{dL}$ & 169 & 54.1 & 13.9 & 94 & 53.8 & 13.2 & 94 & 1.6 & 10.7 \\
\hline women & $\mathrm{mg} / \mathrm{dL}$ & 183 & 67.4 & 17.3 & 96 & 66.6 & 17.1 & 95 & -0.7 & 15.8 \\
\hline
\end{tabular}

I defined by the AHA/NHLBI 2004 [17]; ${ }^{2}$ diagnosis assigned by physician; ${ }^{3}$ difference versus baseline; statistical test applied: t-test; $* \mathrm{p}<0.000$ I. Adjusted for age.

\section{Discussion}

Antihypertensive drugs have been shown to have differential effects on metabolic parameters in clinical trials and recent meta analyses [10]. Treatment with ARBs was associated with a reduced incidence of diabetes mellitus compared to placebo, diuretics and betablockers $[10,19]$. Consistent with this notion Law and colleagues recommend a combination of a standard dose of a RAS blocking agent with low doses of non-RAS blocking agents, as only the RAS blocking agents had no evidence of dose related adverse events [20]. The intention was to achieve substantial reductions in blood pressure with a reduction of drug related side effects. This approach has been well translated into the development of fixed dose drug-drug combinations. In the present non interventional study conducted in primary care a fixed dose combination of $16 \mathrm{mg}$ cande-

Table 2: Cardiovascular risk factors at baseline and follow-up in patients with the metabolic syndrome

\begin{tabular}{|c|c|c|c|c|c|c|c|c|c|c|}
\hline & & \multicolumn{3}{|c|}{ Baseline } & \multicolumn{3}{|c|}{8 weeks } & \multicolumn{3}{|c|}{ Difference $^{2}$} \\
\hline & & $\mathbf{N}$ & mean & \pm SD & $\mathbf{N}$ & mean & \pm SD & $\mathbf{N}$ & mean & \pm SD \\
\hline \multicolumn{11}{|c|}{ Blood pressure } \\
\hline systolic & $\mathrm{mmHg}$ & 1319 & 160.0 & 13.8 & 1312 & 133.3 & 10.4 & 1289 & $-26.6^{*}$ & 14.3 \\
\hline diastolic & $\mathrm{mmHg}$ & 1319 & 94.6 & 8.6 & 1312 & 80.9 & 6.5 & 1289 & $-13.6^{*}$ & 9.2 \\
\hline \multicolumn{11}{|c|}{ Fasting plasma glucose } \\
\hline & $\mathrm{mg} / \mathrm{dL}$ & 1234 & 95.5 & 17.9 & 769 & 92.9 & 14.9 & 764 & $-2.5^{*}$ & 13.1 \\
\hline \multicolumn{11}{|c|}{ Waist circumference } \\
\hline men & $\mathrm{cm}$ & 634 & 107.2 & 11.7 & 599 & 106.1 & 11.8 & 598 & $-1 . I^{*}$ & 4.1 \\
\hline women & $\mathrm{cm}$ & 530 & 97.3 & 13.0 & 498 & 96.7 & 13.3 & 496 & $-0.7^{*}$ & 3.5 \\
\hline \multicolumn{11}{|c|}{ Triglycerides } \\
\hline & $\mathrm{mg} / \mathrm{dL}$ & 1186 & 205.0 & 91.3 & 753 & 185.0 & 74.4 & 741 & $-19.1 *$ & 61.0 \\
\hline \multicolumn{11}{|c|}{ HDL Cholesterol } \\
\hline men & $\mathrm{mg} / \mathrm{dL}$ & 635 & 46.9 & 17.4 & 395 & 47.6 & 13.3 & 384 & I.I* & 11.0 \\
\hline women & $\mathrm{mg} / \mathrm{dL}$ & 526 & 51.3 & 16.6 & 338 & 53.2 & 15.6 & 331 & $2.3^{*}$ & 10.8 \\
\hline
\end{tabular}

I defined by the AHA/NHLBI 2004 [17]; ${ }^{2}$ difference versus baseline; statistical test applied: t-test; ${ }^{*} \mathrm{p}<0.000$ I. Adjusted for age. 
Table 3: Cardiovascular risk factors at baseline and follow-up in patients with Diabetes Mellitus'

\begin{tabular}{|c|c|c|c|c|c|c|c|c|c|c|}
\hline & & \multicolumn{3}{|c|}{ Baseline } & \multicolumn{3}{|c|}{8 weeks } & \multicolumn{3}{|c|}{ Difference $^{2}$} \\
\hline & & $\mathbf{N}$ & mean & \pm SD & $\mathbf{N}$ & mean & \pm SD & $\mathbf{N}$ & mean & \pm SD \\
\hline \multicolumn{11}{|c|}{ Blood pressure } \\
\hline systolic & $\mathrm{mmHg}$ & 1517 & 160.0 & 13.99 & 1489 & 134.1 & 11.2 & 1474 & $-25.9 *$ & 13.7 \\
\hline diastolic & $\mathrm{mmHg}$ & 1517 & 93.4 & 8.46 & 1489 & 81.2 & 6.7 & 1474 & $-12.2 *$ & 9.0 \\
\hline \multicolumn{11}{|c|}{ Fasting plasma glucose } \\
\hline & $\mathrm{mg} / \mathrm{dL}$ & 1302 & 132.0 & 36.8 & 994 & 121.8 & 31.4 & 972 & $-10.8 *$ & 30.1 \\
\hline \multicolumn{11}{|c|}{ Waist circumference } \\
\hline men & $\mathrm{cm}$ & 633 & 109.4 & 12.8 & 601 & 108.2 & 12.2 & 597 & $-1.3 *$ & 2.5 \\
\hline women & $\mathrm{cm}$ & 570 & 100.6 & 14.7 & 530 & 99.5 & 13.6 & 526 & $-0.9 *$ & 2.7 \\
\hline \multicolumn{11}{|c|}{ Triglycerides } \\
\hline & $\mathrm{mg} / \mathrm{dL}$ & 1187 & 205.1 & 104.5 & 834 & 185.6 & 78.4 & 811 & $-23.3^{*}$ & 76.2 \\
\hline \multicolumn{11}{|c|}{ HDL Cholesterol } \\
\hline men & $\mathrm{mg} / \mathrm{dL}$ & 601 & 49.2 & 21.6 & 430 & 48.9 & 16.7 & 420 & $0.5^{* *}$ & 14.36 \\
\hline women & $\mathrm{mg} / \mathrm{dL}$ & 558 & 54.0 & 19.0 & 373 & 54.0 & 17.7 & 361 & $2.0 * *$ & 14.79 \\
\hline
\end{tabular}

\footnotetext{
I diagnosis assigned by physician; ${ }^{2}$ difference versus baseline; statistical test applied: t-test; ${ }^{*} p<0.000$ I; ${ }^{* *} p<0.05$. Adjusted for age.
}

sartan with $12.5 \mathrm{mg}$ HCTZ resulted not only in a strong reduction in blood pressure but also in a favourable change in metabolic risk factors. These changes were more pronounced in high cardiac risk patients like those with metabolic syndrome or Diabetes mellitus compared to patients with neither condition.

\section{Blood pressure reduction}

In the present study a blood pressure reduction of -27.2/$13.4 \mathrm{mmHg}$ was documented. Baseline blood pressure values were comparable throughout the subgroups as was the reduction in blood pressure induced by $16 \mathrm{mg}$ candesartan/12.5 mg HCT. In a previous study patients with previously untreated severe hypertension (mean blood pressure $178 / 117 \mathrm{mmHg}$ ) who received $16 \mathrm{mg}$ candesartan/12.5 mg HCTZ experienced a rapid blood pressure reduction that peaked at $-38 /-29 \mathrm{mmHg}$ [21]. The blood pressure reduction in the present study matches well with previous data and extends these by the finding that patients previously uncontrolled will have a substantial reduction in blood pressure when prescribed the fixed dose combination. The absolute amount of blood pressure lowering (in $\mathrm{mmHg}$ ) appeared to be dependent on baseline blood pressure but did not differ between patient types (diabetes, metabolic syndrome and neither condition). Therefore patients with a higher blood pressure value can expect a higher blood pressure lowering effect of candesartan/HCTZ.

\section{Reduction of cardiovascular risk factors}

Throughout the study a reduction of cardiovascular risk factors was observed. However one should consider the short time frame (observational period 8 weeks) in which the changes were observed and its relative magnitude (Figure 1). While a slight reduction of waist circumference could be observed in all three patient groups, changes were non-significant with respect to fasting blood glucose, triglycerides and HDL cholesterol in patients that neither had the metabolic syndrome nor diabetes (eumetabolic). Patients with metabolic risk factors however showed a pronounced response in these metabolic risk factors when treated with candesartan/HCTZ. Previous studies including the ALPINE (OR 0.12; 95\%CI 0.01-0.97 vs. Thiazides) and the combined SCOPE and CHARM studies (OR 0.80; 95\%CI 0.67-0.95 vs. placebo) have already demonstrated the reduced diabetes incidence in patients taking candesartan $[12,14,22]$. In the randomized double blind ALPINE study newly diagnosed hypertensive patients on a low dose diuretic alone or in combination with a betablocker were compared in their use of candesartan without a calcium channel blocker and followed for a year [14]. At a similar level of blood pressure reduction, patients on the candesartan fixed dose combination had lower levels of plasma glucose, triglycerides and higher HDL-cholesterol. At 12 months, 18 patients in the hydrochlorothiazide group versus five in the candesartan group had a 'metabolic syndrome', as defined by the World Health Organization (P 0.007) despite 1 year of active blood pressure-lowering therapy.

The underlying mechanism for the eumetabolic effects of Candesartan are largely speculative. While there currently is great attention to the PPAR $\gamma$ activating properties of some ARBs [23] candesartan is less lipophilic [24] and 


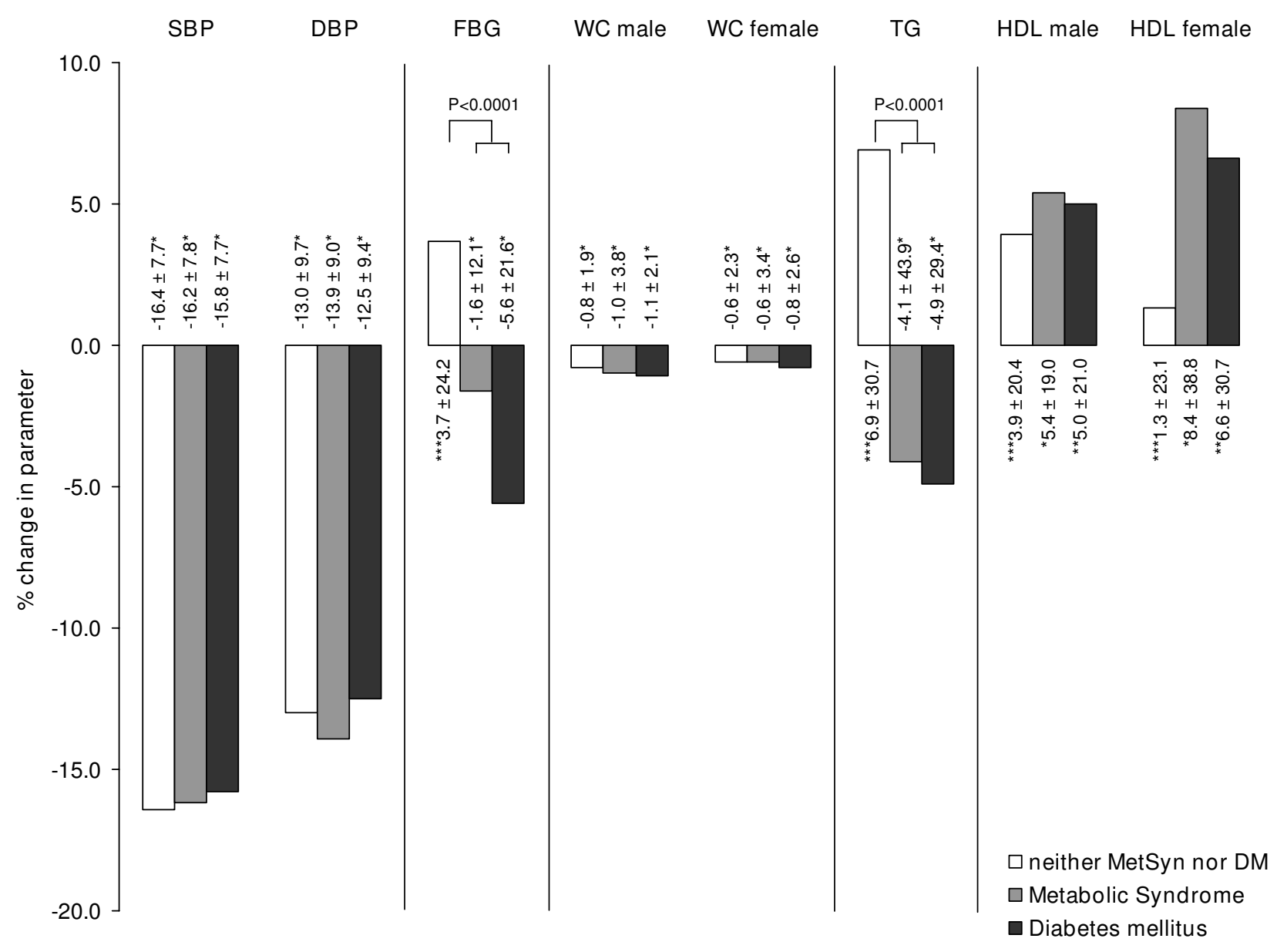

Figure I

Relative change in the single risk factors and of the metabolic syndrome in total. The Metabolic syndrome is given, if 3 out of 5 criteria are met [17]. Significance: $* P<0.000 I$; $* * P<0.05$; *** $\mathrm{P}=$ n.s.; Comparison between groups is a results of ANCOVA analysis (adjusted for age and gender); Differences vs. baseline are compared with a paired t-test (intraindividual comparison).

probably does not directly activate PPAR $\gamma$. It has however recently been reported that candesartan enhanced the gene expression of PPAR $\gamma$ and induced the increased expression of adipokines and a decrease in the proinflammatory cytokine TNF-alpha [25]. On the leptin contrary was reduced because of the repression of the Leptin gene by activated PPAR $\gamma$. Whether this is an adequate explanation for the changes observed can only be speculated at present.

Previous studies in primary care, similar in design as the present study, have shown comparable results to the ones reported here [26,27]. These studies were substantially longer ( 6 and 9 month observations respectively) and point towards the conclusion that the observed effects of candesartan/HCTZ may well be even more pronounced longer term. Differential effects of ARB treatment between patients with and without the metabolic syndrome have also been observed in the study by Kintscher et al. [26], confirming the present result that severely metabolic patients (diabetes > metabolic syndrome) will particularly benefit from an ARB based combination treatment.

\section{Risk for cardiovascular mortality (SCORE)}

Cardiovascular risk scores have been developed to estimate the cardiovascular risk of a given patient. They reflect findings from epidemiological studies like Framingham and PROCAM that a particular set of risk factors makes up the largest proportion of risk. The SCORE method has been developed under the auspices of the European Society of Cardiology (ESC) and has been adapted to fit particular countries in Europe [18] and specific risk tables for 
Table 4: SCORE risk at baseline and follow-up

\begin{tabular}{|c|c|c|c|c|c|c|c|c|c|}
\hline & \multicolumn{3}{|c|}{ Patients without diabetes' or MetSyn ${ }^{2}$} & \multicolumn{3}{|c|}{ Patients with MetSyn² } & \multicolumn{3}{|c|}{ Patients with diabetes 1} \\
\hline & $\mathbf{N}$ & mean & \pm SD & $\mathbf{N}$ & mean & \pm SD & $\mathbf{N}$ & mean & \pm SD \\
\hline \multicolumn{10}{|l|}{ Total } \\
\hline baseline & 225 & 6.4 & 6.0 & 885 & 7.4 & 6.7 & 818 & 19.8 & 14.4 \\
\hline 8 weeks & 139 & 3.5 & 3.1 & 576 & 4.0 & 3.5 & 607 & 11.2 & 8.2 \\
\hline Difference $^{3}$ & 138 & $-2.7^{*}$ & 3.8 & 568 & $-3.2^{*}$ & 3.6 & 590 & $-8.7^{*}$ & 8.7 \\
\hline \multicolumn{10}{|c|}{ Blood pressure alone } \\
\hline baseline & 225 & 6.4 & 6.0 & 885 & 7.4 & 6.7 & 818 & 19.8 & 14.4 \\
\hline 8 weeks & 132 & 6.1 & 5.6 & 557 & 6.8 & 5.9 & 589 & 19.1 & 13.2 \\
\hline Difference $^{3}$ & 132 & $-0.4^{*}$ & 1.2 & 555 & $-0.7^{*}$ & 1.4 & 578 & $-1.4^{*}$ & 3.3 \\
\hline \multicolumn{10}{|c|}{ Risk factors alone } \\
\hline baseline & 225 & 6.4 & 6.0 & 885 & 7.4 & 6.7 & 818 & 19.8 & 14.4 \\
\hline 8 weeks & 221 & 3.9 & 3.4 & 873 & 4.5 & 4.0 & 789 & 12.4 & 8.8 \\
\hline Difference $^{3}$ & 219 & $-2.6^{*}$ & 3.4 & 862 & $-2.9 *$ & 3.3 & 786 & $-7.6^{*}$ & 7.7 \\
\hline
\end{tabular}

I diagnosis assigned by physician; ${ }^{2}$ defined by the AHA/NHLBI 2004 [17]; ${ }^{3}$ difference versus baseline; ${ }^{*} \mathrm{p}<0.000$ I.

Germany have been published [28]. 5\% has been suggested to be the intervention threshold for primary prevention by a working group of the German Society of Cardiology [29].

The documented baseline risk of in the present was well beyond the intervention threshold of 5\% disregarding that most of these patients were eligible for intervention based on a diagnosis of diabetes mellitus or concomitant cardiovascular disease. Treating patients with the fixed dose combination of $16 \mathrm{mg}$ candesartan/12.5 mg HCTZ resulted in a substantial risk reduction. Similar analyses have been conducted in the primary care setting in a previous study. Bramlage et al. showed that Irbesartan treatment (with or without HCTZ) led to a reduction of cardiovascular risk in hypertensive type-2 diabetic patients [30]. The effect was higher in men than in women but no specific data were reported for different patient subgroups. Also no effort was made to attribute SCORE reductions to different risk factors making up the score. Data from the present study point at an only partial responsibility of the blood pressure lowering effect (27.2/-13.4 $\mathrm{mmHg}$ ) but to the favourable metabolic changes induced by candesartan. This was unexpected given the dominant blood pressure lowering effect of the drug and it is also welcome based on earlier data from the Hypertension Optimal Treatment Study, that despite good blood pressure control, the residing metabolic risk factors were found to be an important cause of residual risk [9]. Whether or not a candesartan based treatment may narrow the gap between the cardiovascular risk of naturally normal and well controlled patients is however beyond the scope of the present study.

\section{Limitations}

The present results have to be considered against the background of potential limitations. The study was not controlled and therefore the role of a placebo effect or the withdrawal of antihypertensive agents is unknown. Second, in the absence of a randomization procedure and not consecutive inclusion the influence of unknown biases, e.g. through patient selection, cannot be ruled out. Third, changes in concomitant medication influencing the metabolic profile (lipid lowering agents, oral antidiabetic agents or insulin) have not been documented in the present study. Fourth, randomly high values for blood pressure readings or metabolic changes may have resulted in artificially large reductions consistent with the phenomenon "regression to the mean", the extent of which is difficult to determine. Among the strengths of the study was the choice of the setting. Observational studies in primary care, which include typical patient groups and reflect current treatment approaches, are useful for complementing the findings of randomized controlled trials [31].

\section{Conclusion}

The present study confirms prior results from randomized controlled trials that a candesartan $16 \mathrm{mg} / \mathrm{HCTZ} 12.5 \mathrm{mg}$ based treatment resulted in a good population blood pressure control in actual practice. It further shows that despite concerns about the metabolic effects of diuretics, improvements in metabolic parameters may be seen in patients who receive a low-dose diuretic with candesartan as part of their overall medical care.

\section{Competing interests}

Takeda Pharma GmbH, Aachen, Germany has financed the study. PB has received research support from Takeda 
for the statistical exploration, analysis and the preparation of the manuscript. PO and ES declare that they have no competing interests.

\section{Authors' contributions}

$\mathrm{PB}$ has explored the data, requested statistical analyses from the CRO and wrote the manuscript. PO and ES have revised the manuscript for important intellectual content and have participated in the study conduct. All authors read and approved the final manuscript.

\section{Acknowledgements}

This non-interventional study was conducted by Takeda Pharma $\mathrm{GmbH}$, Aachen Germany. We would like to thank the participating physicians, their assistance and all patients observed during the study. A special gratitude refers to the Clinical Research Organization CFC - Christine Franzen Consulting, Stolberg, Germany for data processing and conduction of the statistical analyses.

\section{References}

I. Sharma AM, Wittchen HU, Kirch W, Pittrow D, Ritz E, Goke B, Lehnert $H$, Tschope $D$, Krause $P$, Hofler M, Pfister $H$, Bramlage $P$, Unger $\mathrm{T}$ : High prevalence and poor control of hypertension in primary care: cross-sectional study. J Hypertens 2004, 22(3):479-486.

2. Kearney PM, Whelton M, Reynolds K, Muntner P, Whelton PK, He J: Global burden of hypertension: analysis of worldwide data. Lancet 2005, 365(9455):217-223.

3. Wolf-Maier K, Cooper RS, Banegas JR, Giampaoli S, Hense HW, Joffres $M$, Kastarinen M, Poulter N, Primatesta P, Rodriguez-Artalejo F, Stegmayr B, Thamm M, Tuomilehto J, Vanuzzo D, Vescio F: Hypertension prevalence and blood pressure levels in 6 European countries, Canada, and the United States. JAMA 2003, 289( ( 8):2363-2369.

4. Ezzati M, Lopez AD, Rodgers A, Vander Hoorn S, Murray C): Selected major risk factors and global and regional burden of disease. Lancet 2002, 360(9343):1347-1360.

5. MacMahon S, Peto R, Cutler J, Collins R, Sorlie P, Neaton J, Abbott R, Godwin J, Dyer A, Stamler J: Blood pressure, stroke, and coronary heart disease. Part I, Prolonged differences in blood pressure: prospective observational studies corrected for the regression dilution bias. Lancet 1990, 335(8692):765-774

6. Lewington S, Clarke R, Qizilbash N, Peto R, Collins R: Age-specific relevance of usual blood pressure to vascular mortality: a meta-analysis of individual data for one million adults in 61 prospective studies. Lancet 2002, 360(9349): $1903-1913$.

7. Mancia G, De Backer G, Dominiczak A, Cifkova R, Fagard R, Germano G, Grassi G, Heagerty AM, Kjeldsen SE, Laurent S, Narkiewicz K, Ruilope L, Rynkiewicz A, Schmieder RE, Boudier HA, Zanchetti A: 2007 Guidelines for the Management of Arterial Hypertension: The Task Force for the Management of Arterial Hypertension of the European Society of Hypertension (ESH) and of the European Society of Cardiology (ESC). J Hypertens 2007, 25(6): I I05-II87.

8. Burke V, Beilin LJ, Cutt HE, Mansour J, Williams A, Mori TA: A lifestyle program for treated hypertensives improved healthrelated behaviors and cardiovascular risk factors, a randomized controlled trial. Journal of clinical epidemiology 2007, 60(2):|33-|4|.

9. Zanchetti A, Hansson L, Dahlof B, Elmfeldt D, Kjeldsen S, Kolloch R, Larochelle P, McInnes GT, Mallion JM, Ruilope L, Wedel H: Effects of individual risk factors on the incidence of cardiovascular events in the treated hypertensive patients of the Hypertension Optimal Treatment Study. HOT Study Group. J Hypertens 200।, 19(6): I I49-II59.

10. Elliott WJ, Meyer PM: Incident diabetes in clinical trials of antihypertensive drugs: a network meta-analysis. Lancet 2007 , 369(9557):20I-207.

II. Scholze J, Grimm E, Herrmann D, Unger T, Kintscher U: Optimal treatment of obesity-related hypertension: the Hyperten-
sion-Obesity-Sibutramine (HOS) study. Circulation 2007, I I5(I5): 199|-1998.

12. Yusuf S, Ostergren JB, Gerstein HC, Pfeffer MA, Swedberg K, Granger CB, Olofsson B, Probstfield J, McMurray JV: Effects of candesartan on the development of a new diagnosis of diabetes mellitus in patients with heart failure. Circulation 2005, I I 2(I):48-53.

13. Zanchetti A, Elmfeldt D: Findings and implications of the Study on COgnition and Prognosis in the Elderly (SCOPE) - a review. Blood Press 2006, I 5(2):71-79.

14. Lindholm LH, Persson M, Alaupovic P, Carlberg B, Svensson A, Samuelsson O: Metabolic outcome during I year in newly detected hypertensives: results of the Antihypertensive Treatment and Lipid Profile in a North of Sweden Efficacy Evaluation (ALPINE study). J Hypertens 2003, 2I(8): 1563-1574

15. Koh KK, Quon MJ, Han SH, Chung WJ, Lee Y, Shin EK: Anti-inflammatory and metabolic effects of candesartan in hypertensive patients. Int J Cardiol 2006, I08(I):96-100.

16. Bramlage P, Schonrock E, Odoj P, Wolf WP, Funken C: [Importance of a fixed combination of ATI-receptor blockade and hydrochlorothiazide for blood pressure lowering in cardiac risk patients. A postmarketing surveillance study with Candesartan/HCTZ]. MMW Fortschr Med 2008, I49(Suppl 4): $172-181$.

17. Grundy SM, Brewer HB Jr, Cleeman JI, Smith SC Jr, Lenfant C, for the Conference Participants: Definition of Metabolic Syndrome: Report of the National Heart, Lung, and Blood Institute/ American Heart Association Conference on Scientific Issues Related to Definition. Circulation 2004, 109(3):433-438.

18. Conroy RM, Pyorala K, Fitzgerald AP, Sans S, Menotti A, De Backer G, De Bacquer D, Ducimetiere P, Jousilahti P, Keil U, Njolstad I, Oganov RG, Thomsen T, Tunstall-Pedoe H, Tverdal A, Wedel H, Whincup P, Wilhelmsen L, Graham IM: Estimation of ten-year risk of fatal cardiovascular disease in Europe: the SCORE project. Eur Heart J 2003, 24( I I):987-1003.

19. Lam SK, Owen A: Incident diabetes in clinical trials of antihypertensive drugs. Lancet 2007, 369(9572):|5|3-|5|4. author reply $15 \mid 4-1515$

20. Law MR, Wald NJ, Morris JK, Jordan RE: Value of low dose combination treatment with blood pressure lowering drugs: analysis of 354 randomised trials. BMJ 2003, 326(7404): | |427-| $43 \mid$.

21. Bönner G, Fuchs W: Fixed combination of candesartan with hydrochlorothiazide in patients with severe primary hypertension. Curr Med Res Opin 2004, 20(5):597-602.

22. Lithell H, Hansson L, Skoog I, Elmfeldt D, Hofman A, Olofsson B, Trenkwalder P, Zanchetti A: The Study on Cognition and Prognosis in the Elderly (SCOPE): principal results of a randomized double-blind intervention trial. J Hypertens 2003, 2 I (5):875-886.

23. Schupp M, Janke J, Clasen R, Unger T, Kintscher U: Angiotensin type I receptor blockers induce peroxisome proliferatoractivated receptor-gamma activity. Circulation 2004, I09( I7):2054-2057.

24. Morsing P, Adler G, Brandt-Eliasson U, Karp L, Ohlson K, Renberg L, Sjoquist PO, Abrahamsson T: Mechanistic differences of various ATI-receptor blockers in isolated vessels of different origin. Hypertension 1999, 33(6): | 406-1413.

25. Zorad S, Dou JT, Benicky J, Hutanu D, Tybitanclova K, Zhou J, Saavedra JM: Long-term angiotensin II ATI receptor inhibition produces adipose tissue hypotrophy accompanied by increased expression of adiponectin and PPARgamma. Eur J Pharmacol 2006, 552(I-3): II $12-122$.

26. Kintscher U, Bramlage P, Paar WD, Thoenes M, Unger T: Irbesartan for the treatment of hypertension in patients with the metabolic syndrome: a sub analysis of the Treat to Target post authorization survey. Prospective observational, two armed study in 14,200 patients. Cardiovasc Diabetol 2007, 6: 12 .

27. Parhofer KG, Muenzel F, Krekler M: Effect of the Angiotensin Receptor Blocker Irbesartan on Metabolic Parameters in Clinical Practice: the DO-IT Prospective Observational Study. Cardiovasc Diabetol 2007, 6(I):36.

28. Keil U, Fitzgerald AP, Gohlke H, Wellmann J, Hense HW: Risikoabschätzung tödlicher Herz-Kreislauf-Erkrankungen: Die neuen SCORE-Deutschland-Tabellen für die Primärprävention. Dt Ärzteb/ 2005, I02:A I808-|8|2. 
29. Gohlke H: [Primary prevention of cardiovascular disease]. Dtsch Med Wochenschr 2005, 130(I-2):38-43.

30. Bramlage $P$, Pittrow $D$, Kirch $W$ : The effect of irbesartan in reducing cardiovascular risk in hypertensive type 2 diabetic patients: an observational study in 16,600 patients in primary care. Curr Med Res Opin 2004, 20(10):1625-1631.

31. Concato J, Shah N, Horwitz RI: Randomized, controlled trials, observational studies, and the hierarchy of research designs. N Engl J Med 2000, 342(25): | 887- 1892.

\section{Pre-publication history}

The pre-publication history for this paper can be accessed here:

http://www.biomedcentral.com/1471-2261/8/30/prepub

Publish with Bio Med Central and every scientist can read your work free of charge

"BioMed Central will be the most significant development for disseminating the results of biomedical research in our lifetime. "

Sir Paul Nurse, Cancer Research UK

Your research papers will be:

- available free of charge to the entire biomedical community

- peer reviewed and published immediately upon acceptance

- cited in PubMed and archived on PubMed Central

- yours - you keep the copyright

Submit your manuscript here:

http://www.biomedcentral.com/info/publishing_adv.asp 